\title{
MODOS DA PAIXÃO EM TROVADORES E MODERNOS
}

Luís Antônio Lindo (FFLCH - USP)

RESUMO: A poesia provençal, no seu culto ao amor, fez da paixão a expressão cultural dum grupo entusiasmado de amantes e aficionados. Praticando a limitação do ato libidinoso na relação amorosa, os trovadores colocaram a paixão acima da ação e inovaram em matéria de costumes. Neste aspecto podem ser considerados precursores do moderno pensamento social que, igualmente destacando o papel da paixão na moralidade, privilegia os direitos sobre os deveres.

Palavras-chave: poesia provençal; paixão x ação, direitos x deveres na moralidade; movimento precursor da modernidade.

E m "O poder do amor", Bernart de Ventadour proclama o seu credo sentimental: "Este amor me fere tão gentil / O coração com um doce sabor / Que cem vezes ao dia morro de dor / E revivo de alegria outras cem. / Este meu mal tão belo parece / Que mais vale este mal que outro bem; / E como meu mal tão bem me faz, / Bom é o bem após o afã." 1

$\mathrm{Na}$ "Invectiva contra o falso amor", Marcabru adverte sobre o poder nefasto deste sentimento: "O Amor é de muito

1 Aquest'amors me fer tan gen / Al cor d'una dousa sabor. / Cen vetz mor lojorn de dolor / E reviu de joi autras cen. / Ben es mos mals de bel semblan, / que mais val nos mals qu'autre bes; / E pois mos mals aitan bos m'es, / Bos er lo bes après l'afan. 
má índole; / Mil homens matou sem espada, / Deus não fez maior mago; / - Escutai! - / Que um néscio do mais sábio / Faz, se o tem a seu lado."2

Essas estrofes exibem dois pontos de vista opostos sobre o amor, o assunto magno da poesia provençal ${ }^{3}$, embora concordem em lhe atribuir grande poder. Os versos de Bernart de Ventadour representam um lugar comum da poesia provençal devotada à paixão, enquanto os de Marcabru fazem o contraponto ao credo da maioria. Para nós, essas visões discrepantes mostram que o chamado "amor cortês" representou ao mesmo tempo uma conquista e um desafio para o mundo que o viu nascer e crescer, bem como para a crítica que leva adiante a sua discussão, forçada a solucionar mistérios e a ocupar posições extremadas para dar conta do significado de motivos quase sempre obscuros e do caráter por vezes indócil dos seus criadores. J. Denomy, sintetizando as opiniões correntes em busca dum significado geral, considerava o amor cortês "uma espécie daquele movimento inerente à alma humana em direção a um objeto desejado"5. Conquanto sucinto e vago, o comentário faz menção a um traço seu essencial, qual seja o de ser intrinsecamente sensual, alheio à mística e à divindade, ao menos nos seus mo-

2 "Amors es mout de mal avi; / Mil homes a mortz ses glavi, / Dieus non fetz tant fort gramavi; -Escoutatz! - / Que tot nesci de plus savi / Non fassa, s’il ten al latz."

3 "A poesia trovadoresca tratou de guerra, política, sátira pessoal e outros temas; mas o assunto que predominou e no qual mostrou a sua originalidade é o amor. Os trovadores foram os primeiros poetas líricos da Europa medieval a lidar exaustivamente com este assunto, e como a sua atitude foi imitada com algumas modificações por poetas franceses, italianos, portugueses e alemães, a natureza do seu tratamento é uma questão de importância considerável." H. J. Chaytor, The Troubadours, p. 14.

4 Para a crítica filológica e literária o assunto "amor" na poesia provençal em geral é tratado sob o epíteto"cortês". Esta qualificação insinuou-se desde que G. Paris a empregou em 1883, num estudo sobre os romances da Table Ronde (Romania, XII). Ressalve-se que, devido às associações indevidas que costuma suscitar, conquanto já incorporada em larga escala na literatura crítica, é preciso empregá-la com cautela.

5 A. J. Denomy, “Courtly love and courtliness”, Speculum, 28, 1, 1953, p. 44. 
numentos mais representativos. Mas atenção, porque lhe é inerente um gesto decisivo em relação à sensualidade, que é o veto à consumação do ato carnal. Nelli, depois de citar uma passagem de Peire Cardenal, o poeta do amor puro, observa que na “idéia de que o desejo 'eternizado' é preferivel ao gozo (que mata o amor), se reconhece um dos princípios mais elevados da ética dos trovadores"6. De fato, é possível pensar que um amor sensual ao qual falta a abastança venérea há de cobrar sua dívida à abstinência, requerendo a obediência de servos e exaltando a honra de cavaleiros. Nas fórmulas rituais duma poesia devotada por vezes à desventura e à mágoa do desterro, suspensa entre a terra e o céu, talvez se possa descobrir algo das razões que levaram os poetas a ficarem amigos da saudade, lutarem contra o dragão da luxúria e até sonharem com algum lugar distante, como no célebre poema de J aufre Rudel, "Princesa de longe": "Diz a verdade quem me chama de ávido / E desejoso deste amor de longe, / Pois nenhuma outra alegria me agrada tanto / Quanto o gozo deste amor de longe. / Mas o que quero me é negado, / Pois assim quis meu protetor / Que eu ame e não seja amado."7

Várias hipóteses já foram levantadas acerca das matrizes da poesia provençal: o neoplatonismo na Idade Média latina (Denomy), a imagística de São Bernardo (Errante), a escola árabe de Toledo (Nykl), as festas de maio (Paris), a emulação de Apuleio e de Asclépio (Silverstein) e ainda outras. Nenhuma delas foi comprovada. Não pretendemos entrar nessa disputa, bastando-nos endossar o ponto de vista decisivo de J. Anglade sobre o assunto: "A antiga poesia provençal se faz notar, desde o princípio, por uma profunda originalidade. Quer pelo fundo, quer pela forma, ela não se assemelha a nada do que a antecedeu. A forma é perfeita, e

6 René Nelli, "L'Érotique des Troubadours", cap. V.

7 "Ver ditz qui m'apella lechay / Ni deziron d'amor de lonh, / Car nulhs autres joys tan noÿm play / Cum jauzimens d'amor de lonh. / Mas so qu'ieu vuelh m'es atahis, / Qu'enaissiÿm fadet mos pairis / Qu'ieu ames e nos fos amatz." 
no entanto ela não tem modelos na poesia clássica dos gregos e dos latinos. As idéias poéticas e os sentimentos expressos pelos primeiros trovadores não denunciam nenhuma imitação; dum extremo ao outro esta poesia viverá por si mesma e não de empréstimos. Esta originalidade, que acabou sendo um elemento de fraqueza, fez no início a sua força." ${ }^{8}$ A. Jeanroy, por dizer algo parecido, também merece ser citado: "A criação própria da França meridional é de uma poesia lírica: criação extremamente original, cuja admiração e imitação impuseram-se à Europa maravilhada até o limiar do Renascimento. Este fascínio se explica pela novidade da tentativa, a primeira feita desde o fim das literaturas clássicas, para encerrar numa forma erudita concepções nobres ou refinadas." Outros fatores determinantes para a originalidade também devem ser considerados: a langue d'oc, o primeiro idioma empregado na produção de alta poesia em língua vulgar no Ocidente medieval, e, saindo do seu ventre como um filho igualmente prolífico, um vocabulário cristalinamente poético, que se tornará o modelo para a emulação lírica nas demais línguas românicas em formação ${ }^{10}$. Ademais, cumpre estar atento ao que forneceu a paisagem física e humana da França meridional, herdeira da civilização romana. Os que contam o que lá existiu, como Capefigue, falam dum magnífico ambiente onde a graça e os afetos bem puderam habitar os espíritos mais sensíveis e tecer histórias entre a realidade e a fantasia. "Os romanos, diz ele, assinalaram tudo em sua pas-

8 J. Anglade, Les Troubadours, p. 74.

9 A. Jeanroy, La Poésie Lyrique des Troubadours, I, p. 61.

10 A esse propósito, o trabalho pioneiro de F. J. M. Raynouard em reintroduzir na filologia moderna o interesse por tudo que a língua provençal e o seu rebento literário significaram será sempre lembrado, através de obras como Des Troubadours et des Cours d'Amour, Éléments de la Grammaire de la Langue Romane, avant l'An 1000; Grammaire Romane, ou Grammaire de la Langue des Troubadours; Influence de la Langue Romane Rustique sur les Langues de l'Europe Latine; Recherches sur l'Ancienneté de la Langue Romane; e o Lexique Roman ou Dictionnaire de la Langue des Troubadours. 
sagem dum caráter de grandeza e de beleza particular. Ape-

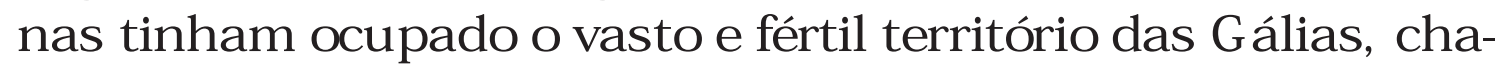
mado Provincia, encerrado entre os Alpes, o mar, o Var e o Rhône, elevam opulentas cidades e fundam ricas colônias: Forum Julii (Fréjus) com seus templos de mármore branco; Antipolis (Antibes), célebre por seus banhos gregos, seus circos, seus teatros; Saint-Maximin, estação militar; Aix, a cidade das águas borbulhantes com suas vinte fontes, que davam saúde e vida aos veteranos das legiões; Apt sobre os pequenos Alpes, AptaJulia, a cidade querida de César; Avignon, filha grega de Marselha; Arles, cidade imperial que possuía a obra-prima da escultura antiga, a Vênus de formas divinas; Saint-Rémy, com seu mausoléu de esbeltas cúpulas, de esguios colunelos, modelo eterno do belo, e Saint-Chamas, orgulhosa de seus pórticos." 11

De todos os ingredientes que entram na composição da poesia provençal, o amor é o que menos admite mistura ${ }^{12}$. Os poetas que guardavam o seu segredo tinham-no por ouro de altíssima pureza e não o retratavam em seus episódios líricos senãojunto à matéria poética mais refinada que podiam apreender e expressar. Sua mensagem está engastada em delicados arranjos de versos zelosamente metrificados e dirigida exclusivamente às almas gêmeas preparadas para entoar o seu hino de salvação. O troba r clus, o senhal, a divinização da mulher e as cortes de amor são marcas distintivas suas que sugerem um ambiente esotérico adequado à sua produção e fruição. É preciso ver porém que a semente da sua vitalidade reside em grande parte no controle imposto à sexualidade. Embora sensual, lascivo, carnal, o amor cortês congela ante as portas do sexo. Vejamos alguns exemplos tirados de poemas que nos permitam perceber algo da sua real natureza:

11 In Les Cours d'Amour Les Comtesses et Châtelaines de Provence, pp. 1-2.

12 Daí a impropriedade de chamá-lo de "cortês" indistintamente, como sugerido na nota 3. 
Aquele que o amor puro pronuncia / Vive leve, cortês e sábio. ${ }^{13}$

Toda façanha cortês: / Deleite, canção e diversão e riso / Me vem do amor, assim me parece. ${ }^{14}$

Que o amor faz bem tudo o que deve fazer, / Pois ele entra nas amadas e nos amantes / Donde neles nasce cortesia e valor / E tudo o que ao verdadeiro mérito pertence. ${ }^{15}$

Se o servi, muito por causa do amor mudei, / Se bem que não possa ter mais que isso. / Pois em tantos lugares me fez tão alto e grande / onde sem ele não poderia ter valor, / e muitas vezes me livro da vilania / que sem amor me livrar não saberia. ${ }^{16}$

Por amor estou tão enamorado, / Que de amor são todas as minhas vontades, / Por amor sou cortês e jovem, / Porque de amor são meus feitos e aparência. ${ }^{17}$

Todos os que estimam o valor / Devem saber que de amor / Procedem grandeza e alegre deleite, / Franqueza e humildade, / O prestígio do amor, a submissão honrada, / A gentil estima, alegria, cortesia. ${ }^{18}$

Nos dois versos dos parágrafos iniciais, como vimos, Bernart de Ventadour manifesta o desejo de renovar continuamente o sentimento nele suscitado pelo amor, enquanto Marcabru, ao contrário, repudia esse sentimento, por ver nele

13 “Aicel cui fin'amors causitz / Viu letz, cortes e sapiens." (Marcabru)

14 "Tota corteza fazenda: / Solatz, chanz e jocs e ris, / Mou ben d'amor, so m'es vis." (Pons de la Gardia)

15 "Qu'Amors fai ben tot aisso que deu far, / Qu'en amairitz intr'ez en amadors / Don nays ez ieys cortezi' e valors / E tot aisso qu'en verai pretz perte." (Aimeric de Peguilhan)

16 “S 'ieu l'ai servit, pro n'ai canje d'Amor, / Ab que je puois non agues mas aitan; / Q'en mains luocs m'a faich tant aut e tant gran / Don ja ses lieis non pogra aver honor, / E maintas vetz m'engart de vilania / Que ses Amor gardar no m'en sabria." (Aimeric de Peguilhan)

17 "Per amor sui tan fort enamoratz, / Que d'amor son totas mas voluntatz, / Per amor am cortezi' e joven, / Quar d'amor son mei fag e mei parven." (Peire Vidal)

18 "Tug cilh que amon valor / Devon saber que d'amor / Mou larguez' e guais solatz, / Franchez' et humilitatz, Pretz d'amor, servirs d'onor, / Gen teners, joi, cortezia." (Gaucelm Faidit) 
uma ameaça à sanidade física e mental. Seu repúdio porém é contra o que chama de amors falsa, e não contra o seu oposto, o amors fina ou veraia ${ }^{19}$. $\mathrm{O}$ amor falso seria um sentimento eivado daquele tipo de vício de comportamento que leva a tratar a outra pessoa como um meio e não um fim. Marcabru parece pensar que o amor falso acaba prevalecendo sobre o verdadeiro, independentemente das intenções dos amantes. Num poema seu em que expõe a luta da realidade contra a aparência durante o jogo de sedução, um nobre que insiste e uma pastora que resiste conversam, até que, a um último e inútil aceno do galante gentil-homem, a pastora encerra a cena com esta resposta: "Senhor, a coruja lhe é de mau agouro / Que se um boquiaberto está ante a pintura (a aparência), / O outro espera o cesto (a realidade). "20

Os limites entre o amor verdadeiro e o falso, tal como foram traçados na poesia provençal, já eram objeto de debate para pensadores da época, como por exemplo Avicena. Na sua doutrina sobre o amor, na parte em que trata das potências da alma, ao falar das várias possibilidades de organizar as faculdades, ele expõe a opinião de que a melhor organização é aquela em que as faculdades superiores sujeitam as inferiores. Uma transgressão nessa hierarquia é comparada à ação dum criado que não obedece a seu $\mathrm{amo}^{21}$. A razão para isso é que, entregue aos desejos, o homem se corrompe, sendo "uma verdade incontroversa que, quando um homem deseja à maneira animal, cobre-se de vício e prejudica sua alma

19 Sobre a posição de Marcabru, vide A. Jeanroy, "La première génération des troubadours", III, p. 494, in Romania, 1930.

20 "Don, lo cavecs vos ahura, / que tals bad'en la peintura / Qu'autre n'espera la mana."

21 "Em tudo isso (a faculdade da imaginação) age como um mau criado que seu amo mandou acompanhá-lo como assistente numa empresa importante e que pensa, após a conclusão bem sucedida do trabalho, que foi ele que atingiu o fim almejado, ele sem o seu amo; que seu amo teria sido incapaz de fazê-lo e que ele é o verdadeiro amo -, ao passo que, na verdade, ele apenas contribuiu para o fim almejado, cuja consecução foi planejada por seu amo; mas disto ele nada sabe." Avicena, A Treatise on Love, trad. de E. L. Fackenheim, V, p. 219. 
racional" 22 . O amor sensual não é inteiramente desaprovado, porém. "Se um homem ama uma forma bela com desejo animal, merece reprovação, até mesmo a condenação e a acusação de pecado, como acontece com aqueles que cometem adultério não natural e em geral com as pessoas que se desencaminham. Mas toda vez que ele ama uma forma agradável com consideração intelectual, da maneira que explicamos, então isto deve ser considerado uma aproximação à nobreza e um aumento do bem." 23 O melhor amor desconhece os impulsos da faculdade animal e exclui o sexo fora da união conjugal. O sexo se justifica apenas em nome da propagação da espécie. Quanto ao abraçar e ao beijar, “o propósito aí é se aproximar e se unir. A alma do amante deseja tocar o objeto de seu amor com os sentidos do tato e da visão, e assim se deleita em abraçá-lo. E anseia por ter a verdadeira essência de sua faculdade anímica, seu coração unido ao do objeto de seu amor, e assim deseja beijá-lo. Essas ações não são pois em si mesmas condenáveis." 24

À luz dessa doutrina, Marcabru certamente, mas também os poetas cultores do amor passam todos por sensatos. Pois ela vale tanto para os que rejeitam o amor, quanto para os que nos seus enleios amorosos se limitam à corte e às carícias. Entretanto, a diferença que continua a existir entre as suas opiniões é bastante para separá-los em dois partidos. Pode-se dizer que dum lado, alinhados com Marcabru, estão os que se guiam pela moral, partindo do pressuposto de que o amor e a moral são incompatíveis. Para estes, o importante é saber evitar danos, ainda mais os previsíveis. O outro partido, que não vê incompatibilidade entre o amor e a moral, ou então simplesmente se despreocupa da questão, abriga os que se dispõem a correr riscos junto à paixão e enfrentar os seus

\footnotetext{
22 Ib., p. 221.

23 Ib., p. 221.

24 Ib., p. 222.
} 
efeitos deletérios, conquanto dentro de certos limites. Este grupo parece entender que o enamoramento constitui uma forma elevada de viver e que a satisfação dos sentidos atrai até mesmo os detratores do amor, que, não obstante se empenharem em desencorajá-lo, estão mais obsedados por ele do que gostariam. Mas vejamos como a posição de cada um dos lados se coaduna com o fato de se tratar de poetas. Nesta condição, não cabe falar numa escala de razoabilidade para aplicação a fatos concernentes à criação poética. Os poetas são poetas independentemente de se mostrarem ou não razoáveis em sua vida prática. Tanto Marcabru quanto os amigos da paixão tiram proveito de o amor seguir o seu curso natural através do coração dos homens e fornecer os episódios que julgam dignos de ilustrar em sua poesia. É pois a distância que há entre o que os sensibiliza que causa a divergência mútua. $\mathrm{O}$ fato de um rejeitar o amor e o grupo dos apaixonados aderir à sua causa, louvando-o e ainda se envolvendo pessoalmente numa relação amorosa, oferece não mais que uma ocasião para separá-los em admiradores da sensatez, dum lado, e admiradores do amor sensual, de outro ${ }^{25}$. O culto ao amor, que não é senão a veneração das mulheres (e não a quaisquer mulheres), pela qual o homem- poeta sensual, ao perseguir o objeto de sua paixão, se vê diante de algo digno de admiração e vela continuamente pelo alto conceito que quer ver atribuído à amada, nos ensina algo a respeito dos liames

25 Vale lembrar que estes últimos amenizam o seu comprometimento sensual ao lançarem mão do princípio da medida justa (mesura) que caracteriza o bom amante (fis amans), cujos afetos transitam entre os pólos do desejo e da veneração. C omo mostra J. Anglade, "este amor não é um amor desregrado, passional, como diríamos; as leis a que está submetido se resumem numa lei superior a todas as outras, tal é a "medida". Pensar, falar, agir com "medida", isto é, com sabedoria, conhecimento, reflexão, é o ideal para onde deve dirigirse o perfeito amante." Op. cit., p. 86. Nestes versos de Marcabru se nota como o critério da ponderação moral age antes mesmo de se cogitar da sensualidade: "No lugar onde falta o senso / O homem não observa medida, / Assim diz a gente antiga." "En tal loc fai sens fraitura / On hom non garda mezura, / So ditz la gens anciana." 
que unem admiração e poesia. Assim como o poeta que canta as façanhas do herói o faz por lhe admirar a bravura, não estando ele próprio obrigado a repetir as façanhas e possuir a mesma bravura, conquanto demonstre possuir em si o que de melhor possui o herói, o poeta provençal também admira a sua amada, cujas virtudes quer expressar, e ainda compartilha essas virtudes e as conserva como um prêmio no amor que é capaz de nutrir por ela. O que ela é conclamada a fazer para se mostrar admirável requer o que ele próprio faz enquanto a admira, ou seja, amar. Neste caso, o seu pendor para ela acrescenta ao desejo a admiração, fazendo-o gozar, além do querer sensual, as maravilhas que descobre na natureza da amada, ser admirável aos seus olhos de poeta admirador. E desse êxtase de encantamento brota a poesia, e se compreende afinal o que significa servi-la. A arte de Marcabru, por sua vez, deveria ser julgada pelo mesmo critério da admiração que a anima, apesar da figura invertida do amor que oferece.

A exaltação do amor casto, possibilitado pela distinção entre o amor que tem seu fim no ato carnal e o que a tal renuncia, mostra não só o quanto os poetas tinham consciência das nuanças que cercam esse sentimento e dos riscos que corriam, mas também o quanto mergulharam dentro de si mesmos a fim de operarem modificações profundas do pensar e do sentir. Os novos patamares sentimentais que atingiram propiciaram uma ampliação dos horizontes sentimentais demarcados pela arte, algo que esta está sempre pronta a fazer e da qual costuma se servir a civilização. Num primeiro momento, a renúncia que possibilitou passar de grau na escola sentimental almejava fazer perdurar o sentimento amoroso e transformá-lo no cimento do culto ao amor. Com o tempo, esse gesto se revelou mais poderoso do que parecia à primeira vista. O seu resultado mais impressionante se deu nas esferas da moralidade e da cultura, onde contribuiu para o surgimento de novos costumes e modelos. Por isso, vale a pena conhecer melhor a equação do desejo no amor cortês, 
pois foi em torno deste eixo que passou a girar a iniciativa de introduzir novos hábitos e referências ligados ao relacionamento amoroso. Manter o desejo sob controle, para introduzir em seu lugar uma vontade que trate o seu objeto com reservas, ou seja, vetar a ultimação erótica, mediante o freio ao ímpeto libidinoso, é um procedimento tido por necessário à implantação do culto ao amor, o qual requer estimar no mais alto grau o mérito da amada. A exaltação do amor inocente que mantém a coesão do grupo encarregado do culto se traduz num aumento da emotividade. $\mathrm{O}$ desgaste emocional diante da interrupção voluntária do ato que realizaria o desejo é recompensado por uma motivação tendente a encorajar atitudes enobrecedoras do sentimento amoroso, enquanto se evita o malefício causado por uma ação lesiva à dignidade do amor. A compensação pela coarctação do gesto antinatural de controlar o desejo toma forma nos ritos do culto e na expressão maravilhada das transfigurações do espírito tomado pela paixão. Um estado sentimental parecido com esse experimentado pelos poetas e que pode servir como referência é o dos que devotam um permanente amor à divindade. Como mostram estes casos, um sentimento que aspira a fundir uma natureza limitada a um ser situado além dos limites de realização da vontade humana pode sofrer uma amplificação antes que o contrário, conquanto possa se mostrar perturbador do ponto de vista da economia psicológica. Da mesma maneira, pode-se afirmar que a divinização da mulher na poesia provençal gerou emoções que se traduziram em motivação para os padecentes do amor perseguirem o seu ideal particular, guardadas as devidas proporções.

As emoções tal como as despertou o culto ao amor têm uma outra peculiaridade que permite associá-las a disposições psicológicas que acabaram por tomar formas culturais características. Refiro-me ao lugar conferido à passividade, em consequência da não realização da vontade e a concomitante suspensão da ação ligada à consumação do ato sexual. Aqueles versos de B ernart de Ventadour do início são 
eloquentes a respeito: "Este amor me fere tão gentil / O coração com um doce sabor / Que cem vezes ao dia morro de dor." Mas atenção, porque esse sofrer tem um "doce sabor" que realimenta incessantemente o ânimo do poeta, que pode então dizer: "E revivo de alegria outras cem / Este meu mal tão belo parece / Que mais vale este mal que outro bem; / E como meu mal tão bem me faz, / Bom é o bem após o afã." O lamento pelo amor não realizado, tão comum nas canções provençais, nos faz ver um dado fundamental: a paixão que subordina a ação e estende o seu domínio sobre a imaginação e a vontade ${ }^{26}$. É mais ou menos natural que a poesia privilegie o momento apaixonado, quando o pathos inclina o espírito a sensações duradouras e sedutoras e cria as condições para a expressão poética, mas é inusitado ver o pathos dominar a vida espiritual a ponto de estabelecer regras próprias tendentes a criar um hábito. Na poesia provençal, porém, é exatamente isso o que acontece. A paixão constitui a lei que governa a vontade, devendo tornar-se o padrão para a conduta dos associados ao seu círculo ${ }^{27}$. Poetas, amadas e seus maridos (muitas vezes), assistentes jograis e audiência estão desse modo reunidos em corpo e espírito para reverenciar o amor e sobretudo para reivindicar o direito a sofrer por amor. O mais extraordinário é que essa fraternidade de amantes, já nos albores da Europa medieval, consegue prenunciar uma moralidade e costumes que só nos tempos modernos serão generalizados. Nesse sentido, constituem um prelúdio do que estará em voga muitos séculos mais tarde.

26 "Uma vez que a complacência na conquista da amada pode levar ao repouso no objeto amado e daí à saciedade, o amor trovadoresco deve permanecer desejo, um anelo implacável. Em sua forma mais pura, ele rejeita a posse física porque, uma vez consumado, o desejo diminui e tende a desaparecer." (A. J. Denomy, "Courtly love and courtliness", op. cit, p. 44.

27 A organização material do movimento trovadoresco é bastante eloquente a respeito das práticas orientadas pela paixão. Sobre a ampla difusão da literatura e da moda provençal e a modificação de costumes que trouxe aos seus aficionados, leia-se, de C. Fauriel, Histoire de la Poésie Provençale, t. 3, cap. XXXVIII, p. 219 ss. 
Para se entenderem os elos aqui sugeridos entre dois períodos históricos distantes entre si é preciso chegar ao que os une. $\mathrm{O}$ fato que nos parece mais visível a esse propósito é o estatuto dado em ambos à paixão. No amor cortês, o desejo marca a relação do apaixonado com o mundo exterior, criando a perspectiva cognitiva que vai do mundo para a mente. $\mathrm{O}$ poeta faz ao mundo solicitações que não podem ser atendidas, de modo que inexiste uma contrapartida no mundo real para tudo o que a sua mente apaixonada está disposta a conhecer ou perceber, sob a influência da emotividade. Na verdade, pode-se dizer que as coisas no mundo que não correspondem ao seu desejo são-lhe muitas vezes irrelevantes ou mesmo desconhecidas. Isto porque a vontade, nesses casos, anseia pelo que não existe e porfia para que o mundo se faça à sua imagem. Parte do que o apaixonado guarda para si na forma de fundo emocional individual serve para criar o seu mundo, o reino da subjetividade expresso pelo poeta (como é o caso aqui) por meio de palavras de emoção. Se pensarmos na relação amante- amada, temos uma situação em que o amor do amante mais determina a amabilidade da amada do que o contrário. Isso é coerente com a disposição dos trovadores em fortalecer o lado da subjetividade, em face do desacordo gerado entre subjetividade e objetividade na relação mente- mundo. S ob o influxo do desejo agindo em suas mentes é pensada a relação com o mundo exterior, de modo que o foco passa para o mundo interior do indivíduo, mais especificamente, na poesia provençal, para a vida emotiva ligada primeiramente ao sentimento do amor dirigido ao objeto amado. Ao induzir à direção de adequação do mundo à mente - a nota fundamental da passividade e da subjetividade -, a paixão empenha o seu padecente na busca do sentido correspondente ao sentimento que experimenta. Nessa forma, entra no vocabulário estético, quando então passa a alimentar a poesia e se torna expressão. 
O que vemos acontecer na cultura trovadoresca se repete de certo modo na cultura moderna, onde a mesma palavra paixão dá o tom da subjetividade e da autonomia que a caracteriza. Nesta passagem de Hobbes já se descobre a mesma perspectiva de adequação do mundo à mente que é central para se estabelecer o primado do mundo interior: "E como "ir", "falar" e os movimentos voluntários similares dependem sempre dum pensamento anterior sobre onde, de que maneira e o que, segue-se evidentemente que a imaginação é o primeiro início interior de todo movimento voluntário" (Leviatã VI). A descoberta da intencionalidade como o posto de observação privilegiado que coloca o mundo em desvantagem ou ao menos em alteridade constitui um lugar comum no pensamento dos autores modernos, uma certeza dos novos tempos adquirida porém através dum longo processo de marchas e contramarchas. J. B. Schneewind mostra em que momento essa visão se insinuou na moral: "Durante os séculos XVII e XVIII as concepções adotadas de moralidade como obediência foram cada vez mais contestadas pelas concepções emergentes de moralidade como autogoverno. Na concepção mais antiga, a moralidade deve ser entendida na sua profundidade como um aspecto da obediência que devemos a Deus. Além disso, a maioria de nós está numa posição moral na qual devemos obedecer a outros homens. (...) A nova perspectiva que emergiu no fim do século XVIII centrava-se na crença de que todos os indivíduos normais são igualmente capazes de viver juntos numa moralidade de autogoverno. Todos nós, nessa visão, temos u ma capacidade igual de ver por nós mesmos o que a moralidade requer e somos em princípio igualmente capazes de agir de acordo com isso, independentemente das ameaças ou recompensas que venham dos outros. (...) A concepção de moralidade como autogoverno proporciona uma moldura conceitual para um espaço social no qual cada um de nós pode pretender dirigir suas ações sem a interferência do estado, da igreja, dos vizinhos ou dos que se pretendam me- 
lhores ou mais sábios que nós. A concepção mais antiga de moralidade como obediência não tinha essas implicações." 28

A nova orientação revela o caráter antropocêntrico da cultura moderna, em contraste com o caráter teocêntrico da Idade Média e cosmocêntrico da antiguidade clássica. O conhecimento do homem significa agora centrar no indivíduo a busca da verdade, da beleza, em suma, dos significados necessários ao funcionamento da nova cultura. Uma mudança correlativa na orientação moral que podemos perceber é a substituição do antigo conceito de deveres pelo novo conceito de direitos, cujo revigoramento praticamente apagou a importância antes atribuída às normas e diretrizes traçadas visando à prestação de contas ao coletivo social. Essa mudança só foi possível porque no lugar do antigo conceito de virtude, essencial à ordem política nos tempos pré modernos, passou a imperar a paixão, a qual está no cerne da nova moral dos direitos. As ações definidas pela posse da virtude perdem o sentido diante da ânsia de liberdade que vai marcar os novos horizontes da conduta regulada pela paixão. Nesse cenário, o isolamento torna-se um ideal de vida para o indivíduo que se supõe dotado duma personalidade inviolável e propenso a cumprir a função de tabu diante do coletivo esparso a sua volta e reduzido se possível à condição de público. A grande diferença para com a moral pregressa está em que a virtude tinha nela um papel no controle das atitudes. A moral aristotélica, por exemplo, ao dividir as virtudes em morais (ethikai aretai) - as que têm por objeto os atos da vida prática, como justiça, magnanimidade, liberalidade, coragem e amizade -, e intelectuais (dianoetikai aretai) - as que têm por objeto o saber e a contemplação ${ }^{29}$-, ligava-as intimamente às

${ }^{28}$ In The Invention of Autonomy A History of Modern Moral Philosophy, Introdução, p. 3.

29 "A virtude, então, sendo de dois tipos, intelectual e moral, a virtude intelectual deve tanto a sua origem como o seu desenvolvimento à instrução (razão pela qual requer experiência e tempo), enquanto a virtude moral procede sobretudo do hábito." Ética a Nicômaco, II, 1103 a, trad. de W. D. Ross. 
paixões e às ações, procurando adequá-las à medida justa. Nesse caso, a virtude operaria como uma espécie de meio (Ética a Nicômaco, II. 6, 1106b.) capaz de evitar, por exemplo, o excesso de sofrimento. A recusa manifestada na cultura moderna em reconhecer o primado da ação virtuosa nos atos morais corre a par da luta pela liberdade de buscar a própria autonomia. Mas a conquista da autonomia implica por sua vez depender dum exame constante das realizações pessoais, a fim de se aquilatar a eficiência da conduta. A relação mantida com a história, para a qual a modernidade se voltou como a um tribunal montado para o julgamento das atitudes tomadas em prol da liberdade, representa algo de fundamental que explica em parte essa dependência. A confrontação com o tempo histórico passa a inquietar as consciências, porque a cada novo passo supostamente dado à frente vem a desconfiança sobre o quanto e como se avançou em relação ao passado.

Diante desses fatos, os paralelos entre o movimento trovadoresco e o estado de espírito moderno saltam à vista: ambos experimentam a mesma escalada sentimental promovida pela entrega à paixão. Assim como a poesia provençal se caracterizou pelo relativo desprezo dos amantes pelo que não estivesse circunscrito ao seu próprio círculo pessoal ${ }^{30}$, o espí-

30 Uma manifestação clara disso era a chamada cultura da vassalagem, que ligava os amantes entre si através dum código de conduta alheio ao que predominava no resto da sociedade. A vassalagem devida pelo amante à amada é um dos traços mais notáveis do "serviço" amoroso. Como diz J. Anglade: "O amante se torna o servo da gleba da pessoa amada, ou mesmo do amor personificado; cumpre suas vontades, obedece a suas ordens, executa seus menores caprichos. Estar enamorado, na poesia dos trovadores, é prestar um juramento, como um cavaleiro." Op. cit, p. 77. Estes versos de Bernart de Ventadour ilustram esse ponto: "Boa senhora, nada vos peço / Senão que me tomeis por servidor, / Pois vos servirei como a bom senhor, / Qualquer que seja o ganho. / Eis-me aqui às vossas ordens, / Franco coração humilde, alegre e cortês!" "Bona domna, re noÿus deman / Mas queÿm prendatz per servidor, / Qu'eÿus servivai com bo senhor, / Cossi que del gazardo m'an. / Veÿus m'al vostre comandamen, / Francs cors umils, gais e cortes!" Outro pormenor a destacar sobre a exclusividade requerida na relação entre os amantes é a preocupação em manter distantes os ciumentos e invejosos, donde o surgimento de obrigações estritas entre os amantes e a prática do senhal para ocultar a identidade das amadas. 
rito moderno conhece um fechamento semelhante, na forma de reposicionamento da moral, que passa a ter por eixo a autonomia e a entronização dos direitos. Neste particular, o ethos trovadoresco também pregava o direito de seus membros viverem plenamente a experiência do arrebatamento amoroso. C om tendência a se generalizar entre os trovadores e o homem moderno, a moral baseada na reivindicação de direitos compete com a moral do dever, apoiada na prerrogativa da ação. Na prática isso se mostra possível porque o eixo da moralidade, ao tender para a paixão em prejuízo da ação, continua fazendo funcionar o mecanismo das relações sociais que dela dependem. $\mathrm{O}$ pensamento motriz do ato moral e fonte da formação de regras de conduta tanto pode guiar-se pelo princípio da ação e o cumprimento do dever, quanto, ao contrário, render-se aos apelos dos sentimentos e à solicitação dos direitos, uma vez que é plausível pensar a intercomunicação entre a ação e a paixão ${ }^{31}$.

Como consequência do papel exercido pela passividade na exaltação do indivíduo, quer no círculo restrito do movimento trovadoresco, quer no contexto social da moral moderna, estamos diante do interesse por instituir uma ordem de valores particular. A nova ordem tal como a conceberam os trovadores, a qual tomava da paixão as regras de prudência, está insinuada nos poemas e tem sido registrada nos relatos históricos e na literatura crítica acerca do movimento. Por exemplo, uma importante norma de conduta tradicional que chegou a ser contestada sob a moda do amor foi a obrigação de respeitar o matrimônio, ficando-se à beira de admitir o

31 Vale lembrar, por aplicável a este caso, o tratamento dispensado por Descartes à relação entre ação e paixão: "Tudo o que se faz ou acontece de novo, disse ele, é geralmente chamado pelos filósofos uma paixão em relação ao sujeito a quem acontece, e uma ação em relação a quem faz com que aconteça; de modo que embora o agente e o paciente sejam em geral muito diferentes, a ação e a paixão não deixam de ser sempre uma mesma coisa que possui esses dois nomes, em virtude dos dois sujeitos diferentes aos quais se pode relacioná-la." Passions de l'Âme, 1, art. 1. 
adultério ${ }^{32}$. Chegar a esse termo implica o repúdio aos deveres que preservam os costumes dos que optaram por se casar. Desse modo, um grupo restrito, por sua atitude extravagante, propõe o direito de viver como ordenado pela vontade. À medida que o dever de respeitar o matrimônio recua ante o direito de amar, nas situações particulares regidas pelo mandamento do êxtase amoroso, observa-se uma reação à cultura dominante ainda devotada ao cumprimento das obrigações próprias à vida social, o que importa em reduzir ou ao menos modificar uma importante gama de ações até então consideradas parte do plano geral dos deveres que rege a vida em comum. Se essa sociedade se sente de fato ameaçada ou se está disposta a tolerar as transgressões não nos importa aqui tanto quanto assinalar o efeito causado pela nova moda

32 O uso frequente do senhal que dá um nome fictício às damas serve para despistar os bisbilhoteiros de toda índole e proteger as amadas. Este artifício torna-se necessário, pois, como nota J. Anglade, "os trovadores só dirigem suas homenagens a mulheres casadas; cantar o amor duma donzela é excepcional na poesia provençal." Les Troubadours, op. cit, p. 79.

33 Quando Aristóteles distinguiu entre virtudes intelectuais e virtudes morais, via nestas as que são implantadas por meio da repetição daqueles atos sociais que levam à fixação de costumes. Por esse prisma, a virtude, que consiste numa disposição para cumprir certos atos morais, traz consigo um imperativo de ordem. O repúdio à regulamentação explica em parte por que a moral no pensamento moderno procura livrar-se da virtude, enquanto investe contra a ordem estabelecida e dá ênfase à experiência dos grupos restritos e do indivíduo isolado. Percebe-se então como a transgressão das regras de prudência estabelecidas pela maioria implica um abalo nas estruturas tradicionais. Uma figura que por muito tempo encarnara a virtude, como o sábio, o qual devia a sua sabedoria à posse de qualidades que tornavam os seus atos benéficos ao meio social, é pouco a pouco substituída por figuras novas possuidoras de outros méritos. No seu lugar, sobretudo nas primeiras afirmações da modernidade, surge a figura do gentil-homem e do dandy, dentre outros espécimes similares, cuja extravagância e singularidade são elevadas ao grau de qualidades máximas presentes tão-só nos indivíduos considerados especiais. No período em que a posse da virtude ainda traçava os objetivos morais, os autores líderes na introdução da modernidade a reverenciavam, conquanto se possa vislumbrar em suas referências a ela algo que não lhe diz exatamente respeito, quando comparado com o que tinham afirmado autores que efetivamente a defendiam, como, por exemplo, os estóicos, pensadores importantes para a compreensão desse tópico. Como representante do novo pensamento, 
sobre a prática tradicional. Essa mudança de orientação moral observada na poesia trovadoresca nada tem de estranho para o pensamento social moderno, no qual a mesma ênfase nos direitos e o rechaço dos deveres é geralmente alardeada por grupos com forte presença cultural e política. O caso da virtude também aproxima os dois campos. Ambos encontram um estado de coisas moral em que a virtude ainda é considerada um valor nas atribuições da vida prática, pela sua função de ordenar a ação. Mas a virtude acaba por perder o seu estatuto em meio ao esforço por reconhecer o primado do individual, à medida que os valores são contados como fazendo parte da esfera da interioridade, como resultado da luta por emancipar a paixão ${ }^{33}$. Também, não se trata mais de controlar os desejos, temendo o mal que possam causar ${ }^{34}$, mas de dar vazão aos sentimentos e tomar a atitude que melhor corresponda aos interesses particulares. Sobretudo nos tempos atuais, a questão não é mais saber ajustar a conduta a regras de prudência pré-estabelecidas, mas deixar-se levar pelo impulso de liberdade ${ }^{35}$. Ao tomar vulto o propósito de erigir uma moralidade legitimada em primeiro lugar pela defesa

temos, por exemplo, Voltaire, que no Dictionnaire Philosophique dizia que a virtude não é tão boa para aquele que a possui, quanto para os outros que a podem aproveitar. Se isto for ponderado, bem se pode entender que a virtude, sob o signo da paixão, venha a ser afinal abandonada como conceito útil pelos grupos propugnadores de conduta excêntrica. Vale lembrar ainda a frase de Rousseau, na Nouvelle Heloïse, III, 18, que revela um aceno à perenidade da virtude no momento em que esta estava para ser soterrada sob a avalanche da nova moda moral que se firmava: "A virtude é tão necessária a nossos corações que, quando abandonamos a verdadeira, fazemos uma a nosso modo, e a retemos talvez com mais força ainda, porque ela representa a nossa escolha."

${ }^{34}$ Ressalve- se que o respeito à medida justa na poesia provençal amenizava essa tendência.

35 No plano político, isto se manifesta no esforço feito pelos grupos combatentes para resolver a questão da formação de governo, no sentido de resolver as contradições inerentes ao problema de ser ao mesmo tempo virtuoso e tecnicamente viável, ou seja, à dificuldade de manter uma administração dos negócios públicos que satisfaça o interesse de minorias, de um lado, e da maioria, de outro. S obre o tema, ver o comentário que acompanha minha tradução dos Paradoxos dos Estoicos, de Cícero. 
dos direitos e não mais pelo cumprimento dos deveres, fica cada vez mais difícil reconhecer a validade dum código ético inequivocamente voltado para o bem coletivo. Em contrapartida, aumenta a prerrogativa do legal como campo de definição para um "deveria" que responda à instabilidade das regras da vida social, aliás, à imposição de novas regras casuísticas em conformidade com os impulsos que caracterizam a vivência do indivíduo e dos grupos formados sob o lema da ética passional ${ }^{36}$. A "política" dos direitos que a isso corresponde promove uma difusão da chamada ética aplicada, a qual opera prudentemente dentro de bolsões sociais onde as reivindicações particularistas se mostrem factíveis e causem uma impressão favorável de comportamento ao mesmo tempo compassivo e progressista. Ao invés do antigo plano de vida emoldurado por deveres de aplicação praticamente universal, passa a valer a experimentação e o incondicionado na conformação das atitudes, exceto pelas condições que oferecem o interesse em usufruir um conceito de vida plena.

Os paralelos que traçamos entre a poesia provençal e o seu culto ao amor e certos aspectos da cultura da modernidade nos levaram a afirmar algumas identidades entre ambas e até mesmo a ver a primeira como precursora da segunda, sobretudo no que diz respeito à importância que veio a adquirir nesta a passionalidade e a concomitante tendência a colocar os direitos acima dos deveres, fenômenos já típicos no movimento trovadoresco. Pudemos expor certas peculiaridades duma virada cultural que tomou forma primeiramente no

36 Vale lembrar que entre os provençais este fenômeno ter-se-ia insinuado através da suposta instituição das "cortes de amor", em que o judicio dominarum (citado por Andreas Capellanus in De Amore), emitido por damas da corte sobre assuntos amorosos, formaria com o tempo uma jurisprudência vinculante. Sobre as "cortes de amor" falaram extensamente Raynouard (Des Troubadours et des Cours d'Amour) e Caesar de Nostradamus (L'Histoire et Chronique de Provence). Digno de nota também é o Essai sur les Cours d'Amours (trad. de F. de Roisin) de F. Diez. Outra curiosidade relacionada com a propensão à criação de normas específicas na cultura trovadoresca é o título Leys d'Amors dado às regras da poesia provençal compiladas em Toulouse, no século XIV. 
campo estético, até alcançar setores importantes da vida social. Pela dimensão que tomou como movimento literário, cultural e moral, pelo primado que atingiu em matéria de arte e sobretudo pela intuição que tiveram os seus criadores originais, ao fazerem da paixão o cerne da existência, por meio do culto ao amor, a poesia provençal merece ser estudada e analisada mais atentamente nos dias que correm.

\section{BIBLIOGRAFIA}

ANGLADE, J oseph, Les Troubadours, Leurs Vies, Leurs Oeuvres, Leur Influence, Armand Colin, Paris, 1929.

ARIS TÓTELES, Ethica Nicomachea, trad. de W. D. Ross, Oxford, 1925.

AVICENA, A Treatise on Love, trad. de E. L. Fackenheim, Mediaeval Studies

CAPEFIG UE, Les Cours d'Amour Les Comtesses et Châtelaines de Provence, Amyot, Paris, 1863

CHAYTOR, H. J. , The Troubadours, Cambridge, 1912

DENOMY, A. J., "C ourtly love and courtliness", S peculum, 1953

DESCARTES, Passions de l'Âme, Oeuvres, v. 11, ed. C. Adam e P. Tannery, Paris, 1909

FAURIEL, C., C., Histoire de la Poésie Provençale, Paris, 1847

JEANROY, Alfred, La Poésie Lyrique des Troubadours, Privat/ Didier, Toulouse, 1934

SCHNEE WIND, J. B., The Invention of Autonomy A History of Modern Moral Philosophy, Cambridge Univ. Press, 2005

ABSTRACT: provençal poetry, through its love worship, made passion the cultural expression of a elated body of lovers and ardent followers. By refusing to perform the sexual intercourse during the love affair, the troubadours put passion in place of action and innovated in the field of usage. From this viewpoint, they may be considered forerunners of the modern social thought, which, in distinguishing the role of passion in the morality, raised rights above the duties.

Keywords: provençal poetry, passion vs. action, rights vs. duties and the morality, troubadours as forerunners of modernity. 